\title{
Генноинженерная биотехнология
}

УдК $579.852 .11: 579.222: 57 \overline{7} 7.152,3: 321: 579.252$

\section{ГЕН $\alpha$-АМИЛАЗЫ - МОДЕЛЬ ДЛЯ КОНСТРУИРОВАНИЯ СЕКРЕТОРНЫХ ВЕКТОРОВ}

А. В. Сорокин, Ю. В. Иомантас, А. С. Аваков, В. Г. Богуш, Г. З. Гайда, А. Я. Стронги,, ЮО. Ј. Козлов, А. И. Степанов, В. Г. Дебабов

Введение. Многие виды бацилл являются промын.ленын продуещтами секреториых бслков. В настоящес время описано ктолирование нескольких генов, конируюших секреторные белки баныл $[1-3]$. Анапиз пуклеотндых последователыпстей этих генов показал, что все белки синтсзируются в виде предшественников, на $\mathrm{NH}_{2}$-конце которых находится сигнальный пептид, удаляемый в ходе секреции.

Использование регуляторных областей генов, кодируюших секреториые белки, открывает возможности для создания так называемых секреторных векторов, то есть таких векторов, которые обсспечивали бы не только сиптез белков - продуктов чужеродных гснов - но и их транспорт через клеточную мембрану. Хорошей моделью для конструирования таких векторов является ген $\alpha$-амилазы, так как некоторые виды бацилл производят этот фермент в очень больших количествах. Активность гена $\alpha$-амнлазы подвержена сложной регуляции, описан ряд мутаций, влияюших на выражение этого гена.

В настоящей работе описана экспрессия гена $\alpha$-амилазы $B$. amyloliquefaciens $A 50$ в составе рекомбинантных плазмид в клетках $E$. coli и $B$. subtilis и копструировапие секреторных векторов па основе этого гена.

Материалы и методы. В работе использовали штаммы $E$, coli C600, B. subtilis recE4 amy- и B. subtilis amy- npr- sep2 (коллекция лабораторин). Бактерии выращивали в бульоне Хоттингера или в L-бульоне с добавлением соответствующих антибиотиков. Бацитрацин использовали в концентрации 100 мкг/мл. Генетическую трансформацию и выделение плазмид проводили, как описа́но в работе [4]. Эндонуклеазы рестрикции получены от Б. А. Ребентиша (ВНИИ генетики и селекции промышленных микроорганизмов Главмикробиопрома при СМ СССР) или фирмы «Serva» (ФРГ). Іолипуклсотндкиназа получена от Е. Д. Свсрдлова (Ин-т биоорганической химии им. M. M. Шемякина АН СССР), полинуклеотидлигаза и нуклеаза Ва131-ог А. Янулайтиса (ВНИИ прикладной энзимологии, Вильнюс). Фрагмент Кленова ДНКполимеразы 1 E. coli выделен Н. В. Якубовичем (ВНИИ генетики и селекции промышленых микроорганизмов Главмикробиопрома при СМ СССР). Нуклеотидную последовательность ДНК определяли методом Максама-Гилберта [5] или методом Сэнгера [6]. Периплазматическую фракцию белков $E$. coli выделяли по методу, описанному НеІ и Хеппель [7]. Активную $\alpha$-амилазу тестировали ло отщеплению красителя от амилопсктиназура («Calbiochem», США). Лейкоцитарный интерферон $\alpha-2$ человека тсстировали с помощью моноклональных антител фирмы «Celitech» (Англия). Активность интсрферона выражали в мсждународных единицах (МЕ). Удельная активность чистого интерферона $-2-4 \cdot 10^{8} \mathrm{ME} / \mathrm{Mr}$.

Плазмнда, содержащая ген интсрферона, получена от Е. Д. Свердлова. Плазмиды, содержащие укороченный репликол рМХ3О, получены от Л. С. Арутюновой (ВНИИ генетикл І селекции промышленных микроорганизмов Главмикробиопрома ири СM СССР). 
Результаты и обсуждение. $Э$ ксп рессия ген а $\alpha$-а м и лазы в клетках E. coli. Ранее мы описали клонирование гена $\alpha$-амилазы $B$. amyloliquefaciens [4]. В этой работе были исследованы две плазмиды pAA2 и pAA15, которые отличались размером встроенного в них фрагмента (рис. 1). Обе плазмиды обеспечивали синтез активной $\alpha$-амилазы в клетках $E$. coli и $B$. subtilis, одпако выход фермента в клетках, содержащих плазмиду рАА2 был примерно в 10 раз выше, чем для pAA15. Эти плазмиды сильно отличались также по своей стабильности.

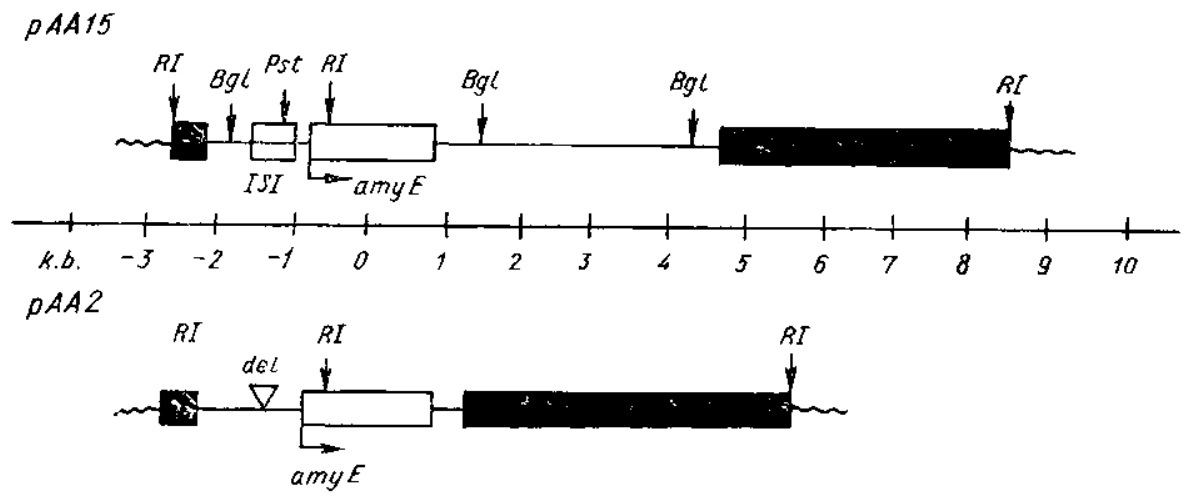

Рис. 1. Рсстрикциониая карта фрагментов ДНК хромосомы $B$. amyloliquefaciens, клонированиых в плазмиде рАA15 и рАA2. Структурный ген $\alpha$-амилазы показан белым прямоугольгиком; черный прямоугольник - ДНК $\mathrm{pBR} 322$; волнистая линия - ДНК pMX30; RI - EcoRI, Bgl-BglII, Pst - PstI; del - предполагаемое положсние делеции в плазмиде рАA2, приводящей к инактивации гена.

Fig. 1. Restriction map of B. amyloliquefaciens A50 DNA fragments, cloned in plasmids pAA15 and pAA2. $\alpha$-amylase structural gene, pBR322 DNA and pMX30 DNA are shown by white box, black box and wavy line, respectively. Bgl - BgliI, Pst - PstI: del - the proposed location of the deletion in pAA2, which causes inactivation of the gene.

Плазмида рАA15 стабильно наследовалась в течение нескольких десятков генсраций, в то время как в популяции клеток, несущих плазмиду рAA2, постоянно появлялись бактерии, нс способные к синтезу $\alpha$ -

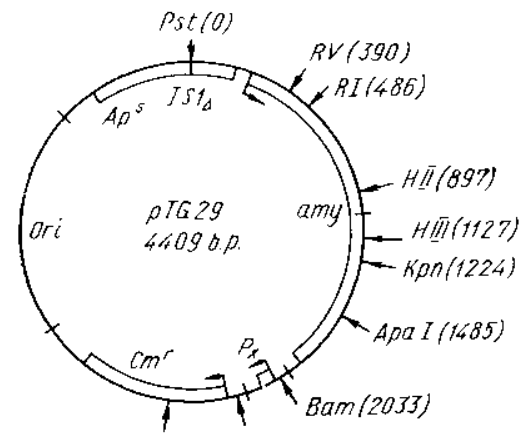

Рис. 2. Рестрикционная карта плазмилы pTG29. Pst - PstI, RV - EcoRV, RI - EcoRI, HII - HindII, HIII - HindIII, Kpn - KpnI, Bam - BamHI; IS1 - дслетированный ISIэлемент.

Fig. 2. Restriction map of pTG29 plasmid. Pst - PstI, RV - EcoRV, RI - EcoRI, HII HindI1, HIII - HindIII, Kpn - Kpnl, Bam BamHI; IS $I_{\Delta}$ - deleted IS 1-element.

амилазы. Анализ плазмидных ДНК, выделенных из бактерий нескольких независимых клонов, показал, что во всех случаях в популяции клеток присутствуют две плазмиды, одна из которых не отличается от pAA2, а другая является ес делсционным вариантом. Все картированные делеции локализуются в области гена $\alpha$-амилазы.

Векторная плазмида рМХ39, которую использовали для клонирования гена $\alpha$-амилазы, имеет большую молекулярную массу $(20000$ пар нуклеотидов) и присутствует в клетках в небольшом числе копий, что сильно затрудняет анализ клонированных на ней фрагментов ДНК. Поэтому для дальнейших исследований мы жлонировали Pst ВатHI-фрагмент плазмиды рAA15 на векторной молекуле pML2.1 [8]. В рсзультате была получена плазмида рTG29 (рис. 2). Клетки E. 
coli, содержащие плазмиду рTG29, устойчивы к хлорамфениколу и синтезируют активную $\alpha$-амилазу. Интересно отметить, что ген устойчивости к хлорамфениколу (САТ) на плазмиде рTG29 не содержит собственного промотора и транскрибируется, по-видимому, с промотора, расположенного на клонированном фрагменте.

Выход активной $\alpha$-амилазы в клетках $E$. coli, несущих плазмиду pTG29, составляет иримерно 40000 молекул на клетку в логарифмической фазе роста, при этом около $80 \%$ активности фермента обна-

\begin{tabular}{|c|c|c|c|c|c|c|c|c|c|c|c|c|c|}
\hline & $31=$ & -1 & & & $R \cdot B$ & . S. & & & met & ile & $g l n$ & lys & arg \\
\hline$\ldots G C$ & $T C A$ & $C G G$ & $A A A A$ & $T G A G$ & $A G Q$ & $G A G$ & $Q G$ & $\triangle A A C$ & $A T G$ & $A T T$ & $C A A$ & $A A A$ & $C \& A$ \\
\hline lys & $\arg$ & thr & $v a l$ & ser & phe & arg & leu & $v a l$ & Leu & met & cys & $t h r$ & teu \\
\hline $\mathscr{A} A G$ & $C G G$ & $A C A$ & $G T T$ & $T C G$ & TTC & $A G A$ & CTT & $G T G$ & CTT & $A T G$ & $T G C$ & $A C G$ & $\operatorname{cta}$ \\
\hline$i e u$ & ohe & val & ser & leu & pro & $i l e$ & $t h r$ & lys & $t h r$ & ser & ala & val & $a_{5 \pi}$ \\
\hline TTA & $T T T$ & $G T C$ & $A G T$ & TTG & $C C G$ & $A T T$ & $A C A$ & $A A A$ & $A C A$ & $T C A$ & $\operatorname{GCC}$ & GTA & $A A T$ \\
\hline 914 & thr & leu & met & $a l n$ & tur & $\begin{array}{l}-152 \\
\text { one }\end{array}$ & glu & $\operatorname{trp}$ & & & & $a \mathrm{cn}$ & 278 \\
\hline$G Q C$ & $A C G$ & $C T G$ & $A T G$ & $C A G$ & $T A T$ & $T T T$ & $G A A$ & $T G G$ & TAT & $\ln r$ & pro & asn & asp \\
\hline & & & & -133 & & & & & IAt & AiL & $\operatorname{cck}$ & $\begin{array}{l}A A C \\
-62\end{array}$ & $\begin{array}{l}G A C \\
\cdots a\end{array}$ \\
\hline$g 6 y$ & $g l n$ & his & tro & 645 & arg & leu & $g l n$ & $a .5 n$ & $a s p$ & $a t a$ & $g l u$ & nis & leu \\
\hline$G G C$ & $C A Q$ & CAT & $T G Q$ & $A A A$ & $C G A$ & $T T G$ & $C A G$ & $A A T$ & $G A T$ & $G C G$ & $G A A$ & $C A T$ & TTA \\
\hline ser & $a s p$ & ile & $g<y$ & ile & thr & $a<a$ & ral & tro & ile & pro & pro & $a<a$ & tyr \\
\hline$T C G$ & $G A T$ & $A T C$ & $G G A$ & $A T C$ & $A C T$ & $G C C$ & GTC & $T G G$ & $A T T$ & $C C T$ & $\mathrm{CCC}$ & $G C A$ & $T A C$ \\
\hline & ECORV & & & & & & & & & & & & \\
\hline tys & gly & thr & ser & $g i n$ & ser & $a s p$ & asn & $g<y$ & $t y r$ & $g l y$ & pro & tyr & $a s, 0$ \\
\hline$A, A A$ & $G G A$ & $A C Q$ & $A G C$ & $C A A$ & $T C C$ & $G A T$ & $A A C$ & $G G A$ & $T A C$ & $G G A$ & CCT & $T A T$ & $G A T$ \\
\hline leu & tyr & asp & leu & $g<y$ & $g l u$ & phe & $\cdots$ & & & & & & \\
\hline TTA & $T A T$ & $G A T$ & TTA & $G G A$ & $G A A$ & TTC & $\cdots$ & & & & & & \\
\hline - & $\begin{array}{r}278 \\
-\quad 1\end{array}$ & $\rightarrow$ & & & & & & & & & & & \\
\hline
\end{tabular}

\begin{tabular}{|c|c|c|c|}
\hline$T G_{4} 62$ & MIQKRKRTVSFRLVLMCTLLFVSLPITKTSA & VNGTLMQYFEWYTP & $E N$ \\
\hline $0 T G_{\Delta} 133$ & MIQKRKRTVSFRLVLMCTLLFVSLPITKTSA & $V N G T \angle M$ & $E N \ldots$ \\
\hline$\rho T G_{\Delta} 278$ & MIQKRKRTVSFRLVLMCTLLFVSLPITKTSA & 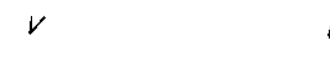 & GEF.. \\
\hline$p r G_{\Delta} 152$ & MIQKRKRTVSFRLVLMCTLLFVSLP & & $R I$. \\
\hline
\end{tabular}

Рнс. 4. a) Нуклеотидная последоватсльность лидерной части гена $\alpha$-амилазы, клонированого в плазмиде pAA15; ISI — начало последовательности IS1-элемента; R. B. S.- сайт связывания с рибосомой гена $\alpha$-амилазы. б) Аминокислотныс послецовательности, кодируемые лидерными областями плазмид, которые могут быть использованы в качсстве секреторных векторов.

Fig. 4. Nucleotide sequence of the leader part, $\alpha$-amylase gene cloned in plasmid pAAl5 (a): ISI - the start of ISl-element sequence; RBS - ribosome binding site of $\alpha$-amylase gene; amino acid sequences coded by plasmid leader sequences which might be used as the secretion vectors $(\sigma)$.

руживастся в периплазматическом пространстве. Выделенная из E. coli ф-амилаза не отличается по молекулярной массе (рис. 3 , см. вклейку) u другим характеристикам от фермента 113 B. amyloliquefaciens. Эти данные показывают, что система секреции $E$. coli узнает сигналы, закодированные в структуре $\alpha$-амилазы, и обеспечивает процессинг и секрецию этого белка в периплазму.

Для BgIII-фрагмента плазмиды рAA15, содержашего ген $\alpha$-амилазы, была определена нуклеотидная последовательность. Фрагмент этой последовательности представлен на рис. 4 (полная последовательность будет олубликована позднее). Как видно нз этого рисунка, в плазмиде рAA15 пронзошло встраивание ISI-элемегта в область, расположенную между промотором и SD-последовательностью гена $\alpha$-амилазы. Этот результат позволяет объяснить различия в уровне синтеза $\alpha$-амилазы, наблюдаемые для клеток с плазмидами рАA2 и 
pAA15. По-видимому, накопление $\alpha$-амилазы в $E$. coli токсично для клеток. Поэтому при культивировании бактерии, утратившие способность синтезировать фермент, получают селективные преимущества. Потеря плазмиды предотвращалась добавлением в среду антибиотика, вследствие чего происходил отбор бактерий со структурными перестройками плазмидной ДНК. В случае плазмиды рАА15 произошло встраивание ISI-элемента, которое привело к снижению синтеза $\alpha$ амилазы и стабилизации плазмидных клеток. Для клеток, несущих плазмиду рАA2, в которую такого встраивания не цроизошло, наблюдается непрерывное расщепление популяции. Интеграцию ISI-элемента в ген $\alpha$-амилазы $B$. coagulans наблюдали также Kориелис и др. [9]. Интерссно отметить, что встраивание IS1-элемента между промотором и участком инициации трансляции гена $\alpha$-амилазы не блокирует полностью экспрсссию гена. Более того, удамение промотора $\alpha$ амилазы (плазмида рTG29) также не останавливает транскрипцию. Извсстно, что в состав IS1-элемента входят терминаторы транскриппии и за счет этого встраивание IS1 обычно приводит к инактивации гснов и оперонов [10]. Анализ нуклеотидной последовательности плазмнды рTG29 не выявил перед геном $\alpha$-амилазы структуры, соотвстствующей обычным промоторам $E$. coli. Таким образом, остается неясным, с какого промотора осуществляется транскрипция гена $\alpha$-амилазы на плазмидах рТG29 и рАA15.

За последовательностью гена $\alpha$-амилазы обнаружена шпилечная структура, характерная для бактериальных терминаторов транскрипшии. Далее паходится последовательность, гомологичная вегетативным промоторам бацилл. Удаление этой области из плазмиды рTG29 приводит к утрате клеткамк, содержащими плазмиду, устойчивости к хлорамфениколу. Следовательно, этот промотор функционален 3 клетках E. coli.

Экспрессия гена $\alpha$-амилазы в клетках $B$. subtilis. Для изучения экспрессии гена $\alpha$-амилазы в клетках $B$. subtilis была сконструирована плазмида рKB8 (рис. 5), которая содержит PsII - ВатHI-фрагмент плазмиды pTG29, клонированный на делеционном варианте вектора pMX30. Қлетки B. subtilis 168 amy-, получившие такую плазмиду, про-

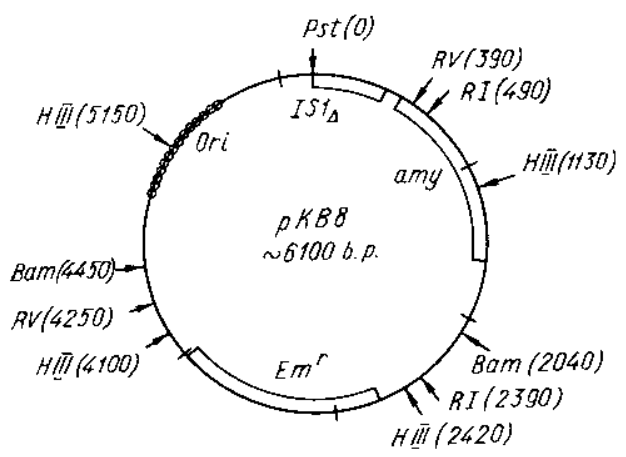
дущируют активную $\alpha$-амилазу, однако в очень малых количествах. Напомним, что плазмида

Рис. 5. Рестрикционная карта плазмиды рКВ8: Ori - укорочелный ориджин

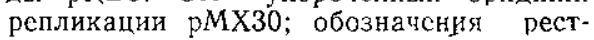
риктаз, как на рис. 2.

Fig. 5. Restriction map of pKB8 plasmid: ori-the shortened origin of replication of pMX30; abbreviations of restriction enzymes are identical to that in Fig. 2.

pКВ8 не содержит промотора $\alpha$-амилазы. Эта плазмида может быть использована для клонирования бациллярных промоторов, причем относитсльную силу промоторов можно оценивать in vivo по размеру зон гидролиза крахмала или амилопектиназура на индикаторных чашках.

Мы использовали плазмиду рҚВ8 для клонирования промотора $\alpha$ амилазы. В результате была получена плазмида pRT5 (рис. 6, см. вклсйку), которая обеспечивала высокий уровепь синтеза $\alpha$-амилазы (около 400 мг/л культуры за 24 ч ферментации). Практически весь фермент (более $99 \%$ ) был обнаружен в культуральной жидкости. Синтезируемая $\alpha$-амилаза по молекулярной массе, иммунологическим свойствам и удельной активности не отличалась от фермента из исходного штамма $B$. amyloliquefaciens A50. Для фермента, слнтезируемого B. sublilis, была определена N-концевая аминокислотная после- 
довательность, которая полностью совпала с последовательностью зрелого фермента из штамма А50.

Конструи ровани е секреторных векторов. Для получения секреторного вектора мы вводили удобный для клонирования участок расщепления рестриктазы в непосредственной близости от фрагмепта ДНК, кодирующего сигнальный пептид. С этой целью ДНК плазмиды pTG29 (рис. 2) расщепляли рестриктазой EcoRV и затем обрабатывали экзонуклеазой Bal31. Условкя реакции подбирались таким образом, чтобы отщепилось примерно 200 пар пуклеотидов. Для трансформации использовали кольцсвые молекулы, полученные с помощью ДНҚ-лигазы. Отбирали ату--трансформанты, из которых вы-

Рис. 7. Рестрикционная карта плазмиды рTGA6. Обозначения рестриктаз, как на рис. 2. Сверху показано место стыковкн $\alpha$-амилазы с иитерфероном $\alpha-2$. Цистеиновый ко,Һон соотвстствует первой аминокисліоте зрслого интерферо1 a.

Fig. 7. Restriction map of pTGA6 plasmid. In the upper part the fusion of $\alpha$-amylase and interferon $\alpha 2$ is shown. Cys-codon codes the first amino acid of the ma ture interferon. The abbreviation of restriction enzymes are identical to that in Fig. 2.

сигнальный ser alat val gly glu phe met cys

nenmuO TCA GCC GTA GGA GAA TTC ATG TGT... IFN- $\alpha 2$

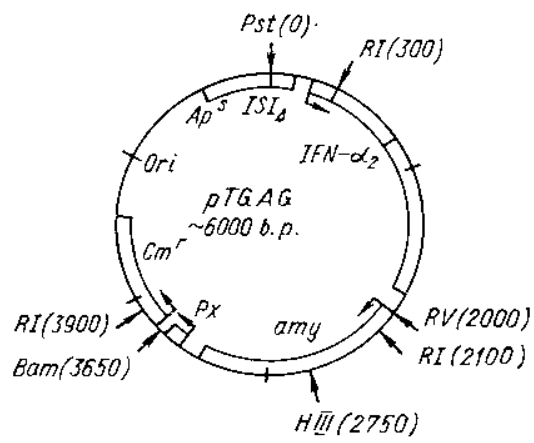

деляли плазмидную ДНК, и после рестрикиионного анализа определяли нуклеотидные последоватсльности в области EcoRI-сайта. Из 200 проанализированных плазмид было отобрано четыре, которые можно использовать в качестве секреторных векторов (рис. 4, б). Одна из глазмид - p гы $_{\Delta} 278$ - была выбрана нами для использования в качествс секреторного вектора при клонировании гена лейкоцитарного интерфсрона чсловека $\propto-2$.

Последовательность ЦНК, кодирующую структурную часть гена $\pi$ лйкоцитарного интерферона, встраивали в EcoRI-сайт плазмилы $\mathrm{pTG}_{\Delta} 278$ (рис. 7). Полученные рекомбинантные молекулы вводнли в клетки $E$. coli C600 и исследовали экспрессию гена интерферона. Оказалось, что в логарифмической фазе роста в клетках накапливается $1 \div 2 \cdot 10^{7} \mathrm{ME}$ интерферона, что соответствуст примерно $10^{3}$ молекул на клетку. Примерно $50 \%$ синтезированного интерферона тестируется в периплазматической фракции, остальная активность обнаруживается в цитоплазме. Препараты интерферона, выделенные из периплазмы и цитоплазмы, чистили на моноклональных антителах и анализировали электрофорезом в полиакриламидном геле с подецилсульфатом натрия (рис. 8, см. вклейку). Оказалось, что интсрфсрон из периплазмы имеет молекулярную массу 19000. Эта молекулярная масса складывается из молекулярной массы зрелого интерферона (18000) и молскулярной массы пяти аминокислот, которые появляются в результате процессинга сигнального пептида, если предположить, что этот процессинг происходит в том же месте, что и у а-амилазы (рис. 4).

Следует отметить, что в цитоплазматической фракции обнаружена вторая форма иммунологически активного интерферона с молекулярной массой 17000. Эта форма, по-видимому, является продуктом деградации интерферона, так как образование пептндов с такой же подвижностью наблюдается и при обработке интерферона некоторыми протеиназами.

Для изучения синтеза и секреции интерферона в бациллах была сконструирована плазмида рRT84.1 (рис. 9), в которую клонировали PstI - BamHI-фрагмент плазмиды pTGA6 (рис. 7), содержащей ген 
интерферона. Плазмиду рRT84.1 - INF вводили в клетки B. subtilis 168 и исследовали накопление интерферона в культуральной жидкости. В этих экспериментах нам не удалось обпаружить интерфероновой активности. Известно, что клетки $B$. subtilis синтезируют и секретируют несколько протеиназ [11]. Действительно, добавление к раствору интерферона культуральной жилкости, полученной после фермептации B. subtilis, приводит к очень быстрой инактивации интерферона. Для підавления протеазно̆ активности в культуральную среду цобавляли бацитрацин. В этом случае в культуральпой жидкости накапливалось до $10^{7} \mathrm{ME} /$ л интерферона. Был сконструирован также мутантный штамм B. subtilis co сниженной активностью металло- и сериновой

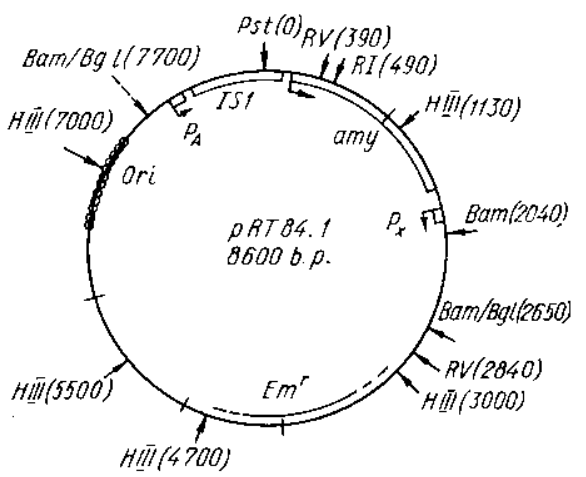

PIс. 9. Рестрикционная карта плазмиды pRT84, 1. Обозначения рестриктаз, как на рис. 2. Плазмида рRT84. 1 -IFN получена клонированием PstI-BamHI-фрагмента плазмиды pTGA6 в плазмидс pRT84. l в клетках $B$. subtilis.

Fig. 9. Restriction map of pRT84. 1 plasmid. The abbreviations of restriction enzymes are identical to that in Fig. 2. Plasmid pRT84. 1-IFN was constructed by cloning Pstl-BamHI-fragment of pTGA6 plasmid in pRT841 plasmid in $B$. subtilis cells.

протеиназ. Этот штамм также продуцировал $10^{7} \mathrm{ME} / л$ интерферона. Примерно половина синтезированного интерферона секретировалась в культуральную жидкость, остальная активность оказалась связанной с клетками и тестировалась только после обработки их додецилсульфатом натрия.

Таким образом, сконструированные пами векторы способны обеспечить синтез и секрецию интерферопа в клетках $E$. coli и $B$. subtilis, однако количество и распределение интерферона и $\alpha$-амилазы между клетоными фракциями сильно различается.

Идея создапия секреторных векторов привлекает в настоящее время все большее внимание. Такие векторы обладают целым рядом потенциальных преимуществ по сравнению с традиционными молекулами, используемыми для экспрессии гепов. Сейчас накапливается все больше данных о том, что суперпродукция очень многих белков токсична для бактериальной клетки. Следовательно, для обеспечения больиего выхода таких белков необходимо обеспечнть их транспорт из клетки.

Секреторные векторы могут также обеспечить и целый ряд технологических преимуществ при использовании штаммов - продуцентов бслков в промышленпости.

Приведенныс в настоящей работе результаты и ряд литературных дапшых $[12,13]$ показывают принципиальную возможность создания секреторных векторов.

Участок инициации трапсляции и лидерный пептнд гена $а$-амилазы B. amyloliquefaciens обеспечивают синтез и по крайней мере частичную $(50 \%)$ секрецию интерферона человека в клетках $E$. coli и B. subtilis. При этом, по-видимому, происходит правильный (с точностью до 1 аминокислотного остатка) процессинг белка. С.тедует, однако, отметить, что выход интерферопа зпачителыно ниже, чем выход $\alpha$-амилазы, ген которой был клонирован в аналогичных конструкциях. Для $E$. coli наблюдаются отличия в $40-50$ раз, для $B$. subtilis - более чем в 1000 раз в слугае штамма с пониженным синтезом протеиназ.

Причины, обусловливающие такую большую разницу в выходе двух белков, в настоящее время не известны. Не вызывает сомнения, что одним из основных факторов является различная чувствнтельность иптерферона и $\alpha$-амилазы к протеолизу. Действительп, синтез иптер- 
ферона в B. subtilis мы смогли обнаружить только после введения мутаций по генам протеиназ, в то время как эти мутации мало сказывались на выходе $\alpha$-амилазы. Интерферон нестабилен также и в $E$. coli, так как в клетках накапливается значительное количество низкомолекулярных продуктов деградации интерферона. Время полураспада интерферона в $E$. coli cocтавляет примерно 1 ч, что значительно ниже соответствующего времени, характерного для обычных бактериалыных белков.

\section{ALPHA-AMYLASE GENE AS A MODEL}

\section{FOR SECRETION VECTOR CONSTRUCTION}

A. V. Sorokin, Yu. V. Jomantas, A. S. Avakov, V. G. B̈ogush, G. Z. Gaida, A. Ya. Strongin, Yu. I. Kozlov, A. I. Stepanov, V. G. Debabov

All-Union Rescarch Institute of Genetics and Breeding

of Industrial Microorganism, Glavmicrobioprom at Cuuncil

of Ministers of the USSR, Moscow

Summary

Bacillus amyloliquefaciens A50 alpha-anylase gene was cloned in E. coli and B. subtilis cells. The leader part of the gene wlich includes the signal peptide coding sequence was used for secretion vector construction. One of the vectors obtained was applied for human leukocyte interferon expression in $E$. coli and $B$. subtilis. The secretion of interferon and alpla-amylase was shown to differ in these microorganisms. A large amount of interferon in $E$. coli is found in cytoplasm while in $B$. subtilis it is found in tlie membrane fraction.

1. Nucleotide sequence of the promoter and $\mathrm{NH}_{2}$-terminal signal peptide region of the a-amylase gene from Bacillus amynoliquefaciets / i. Palva, R. F. Pettersen, N. Kalkkinen et al.-Gene, $1981,15, \mathrm{~N} 1, \mathrm{p} .43-51$.

2. The substilisin $\mathrm{E}$ gene of Bacillus subtilis is transcribed from a $\sigma^{37}$ promoter in vivo / S.-L. Wong. Ch. Price, D. S. Goldfarb, R. H. Dot.-Proc. Nat. Acad. Sci. USA, $1984,81, N 4$, p. $1184-1188$.

3. Brammar W. J., Muir S., McMorris A. Molecular cloning of the gene for the B-lactamase of Bacillus licheniformis and its expression in Escherichia coli.-Mol. and Gen. Genet., 1980, 178, N 1, p. 217-224.

4. Синтез ін сскреция активной $\alpha$-амнлазы Bacillus amyloliquefaciens A50 в клстках Bacillus stibtilis и Escherichia coli/A. В. Сорокин, IО. В. Номантас, В. Е. Ка-

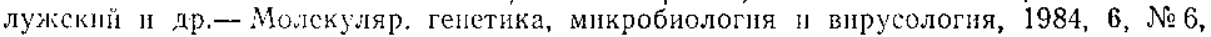
c. $24-26$.

5. Maxam A. M, Gilbert $W$. Sequencing end-labelled DNA with basespecific chemical cleavages.- Metl. Enzvmol., 1980, 65, p. 499-560.

6. Sanger F., Nicklen S., Coulson $\Lambda$. $R$. DNA sequencing with chan terminating inlibitors.-Proc. Nat. Acad. Sci. USA, 1977, 74, N 18, p. 5463-5467.

7. Non H.C., Heppel L. A. The release of entymes from Escherichia coli by osmotic slock and during formation of spheroplasts.-J. Biol. Chem., 1965, 240, N9. p. $3685-3692$.

8. Kлонирование гена фио́областного ингерферона человека в клетках Escherichia coli/1О. И. Қоз.лов, С. В. Машко, М. И. Лебедева и др.-Молекитяр. генетика, микробнология, и вирусология, 1983, 7, № 7, с. 19-23.

9. Cornelis P., Dignoffe C., Willemot H. Cloning and expression of a Bacillus coagulans amylase gene in Escherichia coli.-Mol. and Gen. Genet., 1982, 186, N3, p. $507-511$

10. Besemer J., Herpers $M$. Supression of polarity of insertion mutation within the gal operon of Escherichia coli.- Mol. and Gen. Genet., 1977, 151, N 2, p. 205--302.

11. Pricst F. Extracellular enzyme synthesis in the genus Bacillus.- Bacteriol. Revs, $1977,41, N 3$, p. $711-753$.

12. Secretion of interferon by Bacillus subtilis/I. Paiva, P. Lehtovaara, L. Hääriäinen ct al.-Gene, $1983,22, \mathrm{~N} 2$, p. 229-235.

13. A Bacillus subtilis secretion vector system derived from the $B$. subtilis $\alpha$-amylase promoter and signal sequence region and secretion of Eschericlia coli $\beta$-lactamase by the vector system/K. Ohmura, T. Shraza, H. Nakamura ct al.-J. Biochem., 1984, 95, N 1, p. $87-93$.

ВННИ генетикщ и селекции

Полүчено 03.09 .84

промышлснын микроорганизмов

Главмикробиопрома при СМ СССР, Mockва 